\title{
Analysis on insider trading of backdoor listing of 360 Technology Limited
}

\author{
Xinhong Wang ${ }^{1, a}$, Haoran Zhao ${ }^{2, ~ b, *}$ \\ ${ }^{1}$ School of Management, Xi'an University of Science and Technology, Xian, Shaanxi, China \\ ${ }^{2}$ School of Management, Xi'an University of Science and Technology, Xian, Shaanxi, China \\ bemail-1026603035@qq.com \\ ${ }^{*}$ Corresponding author Haoran Zhao
}

Keywords: Backdoor listing, Insider trading.

\begin{abstract}
Backdoor listing can enable enterprises to go public quickly to raise funds and promote industrial development, but backdoor listing insider trading is an important issue that cannot be ignored. Information leakage will lead to market fluctuation in the backdoor listing. Insider trading will increase the stock price before the backdoor listing, reduce market liquidity and increase the backdoor cost. This article selects this year's hot topics"Backdoor listing of 360 Technology Limited"as a case, combined with the method of market model, stock turnover rate and the change of the number of shareholders analysis before the 360 Technology Limited backdoor listings there is no large-scale phenomena of insider trading, but there are signs that there may be a small insider trading. The government should strengthen the supervision of information disclosure and crack down on insider trading.
\end{abstract}

\section{Introduction}

In the present of the rapid development of Internet, information security is more and more attention, as the domestic information security industry leader in the 360 Technology Limited in February 2018 to return to A-share market in China. The analysis of insider trading in the process of listing enriches the research on the influence of mergers and acquisitions on the efficiency of capital market, and expands the research scope of insider information in mergers and acquisitions In this paper, it is found that there is no large-scale insider trading before backdoor listing of 360 Technology Limited, but there are signs that there may be small-scale insider trading and the implementation of related transactions takes place earlier. This raises the cost of backdoor listing and reduces the efficiency of the securities market. The research conclusion of this paper has important reference value for the regulatory departments to formulate laws and regulations on asset reorganization and information disclosure and improve the listing mechanism of companies.

\section{Analysis of insider trading}

\section{1 market volatility analysis}

The stock price volatility and the super high accumulated abnormal rate before the company's backdoor listing announcement can reflect to some extent whether there is insider trading. The benefit of informed traders is the cost of backdoor companies, which affects the efficiency of resource allocation in the securities market.This paper Use the market model to estimate the normal stock return rate.In the case of market models estimating normal yields,Calculation model of abnormal return rate:

$$
\begin{gathered}
\mathrm{AR}_{\mathrm{t}}=\mathrm{R}_{\mathrm{t}}-\left(\alpha+\beta \times \mathrm{R}_{\mathrm{m}}\right) . \\
\mathrm{CAR}=\sum \mathrm{AR}_{\mathrm{t}} .
\end{gathered}
$$

$A R$ represents the daily abnormal rate of return, $t$ represents date, $\alpha$ and $\beta$ represents the estimated parameters of the regression model using the asset pricing model in the event period of 
300 days, $C A R$ represents the cumulative abnormal rate of return, $R m$ represents the yield rate of the Japanese market (this paper selects the yield rate of Shanghai a-share market). In this paper, the year before suspension is selected as the estimated period. The regression results are shown in table 1 and the accumulated abnormal return rate of 360 trading days before the suspension of trading is shown in table 2:

$$
\mathrm{AR}_{\mathrm{t}}=\mathrm{R}_{\mathrm{t}}-\left(-0.00161+1.453 \times \mathrm{R}_{\mathrm{m}}\right) \text {. }
$$

table 1. Linear regression results of market models

\begin{tabular}{|c|c|c|c|c|c|}
\hline \multicolumn{6}{|c|}{ The model summary } \\
\hline model & \multicolumn{2}{|l|}{$\mathrm{R}$} & \multicolumn{2}{|c|}{ Adjust } & $\begin{array}{l}\text { Estimated } \\
\text { error }\end{array}$ \\
\hline 1 & $.498 \mathrm{a}$ & & \multicolumn{2}{|c|}{.244} & .0176732 \\
\hline \multicolumn{6}{|c|}{ Anovaa } \\
\hline model & $\begin{array}{l}\text { Sum of } \\
\text { squares }\end{array}$ & $\mathrm{df}$ & $\begin{array}{l}\text { mean } \\
\text { square }\end{array}$ & $\mathrm{F}$ & Sig. \\
\hline regression & .025 & 1 & .025 & 79.311 & $.000 \mathrm{~b}$ \\
\hline residual & .075 & 241 & .000 & & \\
\hline total & .100 & 242 & & & \\
\hline \multicolumn{6}{|c|}{ coefficienta } \\
\hline \multirow{2}{*}{ model } & \multicolumn{2}{|c|}{ Non-std.coef. } & \multirow[t]{2}{*}{ Std.coef. } & \multirow[t]{2}{*}{$\mathrm{t}$} & \multirow[t]{2}{*}{ Sig. } \\
\hline & B & Std.err. & & & \\
\hline $\begin{array}{c}1 \\
\text { (constant) }\end{array}$ & -.00161 & .00113 & & -1.417 & .158 \\
\hline variable & 1.453 & .163 & .498 & 8.906 & .000 \\
\hline
\end{tabular}

table 2. The 300 trading days before the suspension accumulated abnormal returns

\begin{tabular}{|c|c|c|c|}
\hline Trading day & CAR & Trading day & CAR \\
\hline 1 & $-0.22 \%$ & 160 & $-14.75 \%$ \\
\hline 3 & $1.03 \%$ & 200 & $-10.21 \%$ \\
\hline 10 & $2.86 \%$ & 220 & $-12.27 \%$ \\
\hline 20 & $-11.17 \%$ & 240 & $-8.72 \%$ \\
\hline 30 & $-8.89 \%$ & 260 & $9.11 \%$ \\
\hline 50 & $-14.96 \%$ & 280 & $8.22 \%$ \\
\hline 70 & $-14.06 \%$ & 300 & $17.21 \%$ \\
\hline 100 & $-14.07 \%$ & 330 & $20.31 \%$ \\
\hline 130 & $-13.95 \%$ & 360 & $17.44 \%$ \\
\hline
\end{tabular}

As you can see from table 2, The abnormal returns of the day before suspension are not obvious,showing a negative growth of $-0.22 \%$. The accumulated rate of 30 trading days before the suspension shows a continuous decline.he maximum of 330 trading days before the suspension was 20.31 per cent.For 300 trading days, The accumulated abnormal returns of the first 160 trading days showed a downward trend. The accumulated rate of the last 170 trading days showed a slow upward trend.The fluctuation range is small and there is no obvious sign of jumping up.In 240 trading days or so the volatility is significant,There may be other good news out there,But the cumulative abnormal returns did not increase significantly at this time.In general, before the listing of 360 Technology Limited backdoor shares, stock movements were not obvious.

\section{2 analysis on the change of turnover rate and number of shareholders}

To further verify the robustness of the supporting conclusions, This paper analyzes insider trading from the change of the number of shareholders. This paper divide 360 Technology Limited trading 
days before suspension into 6 periods on average and Calculate the number of shareholders and the rate of change at each time period. As shown in table 3, Around 105 trading days before the suspension, The number of shareholders is clearly concentrated. The number of shareholder was down 17.94 per cent from 165 days before the suspension. At this point, there may be a risk of information leakage leading to equity concentration. However, it is not reflected in stock price volatility, the operation may be relatively hidden and small.

Table 3. The number of shareholders and the shareholding status before the suspension

\begin{tabular}{|c|c|c|c|c|}
\hline Trading day & 0 & 46 & 69 & 105 \\
\hline $\begin{array}{c}\text { Shareholders } \\
\text { (ten thousand) }\end{array}$ & 2.59 & 2.62 & 2.66 & 2.79 \\
\hline Rate of change & $-1.15 \%$ & $-1.50 \%$ & $-4.66 \%$ & $-17.94 \%$ \\
\hline Trading day & 165 & 202 & 271 & 349 \\
\hline $\begin{array}{c}\text { Shareholders } \\
\text { (ten thousand) }\end{array}$ & 3.40 & 3.39 & 2.29 & 2.79 \\
\hline Rate of change & $0.29 \%$ & $48.03 \%$ & $-17.92 \%$ & - \\
\hline
\end{tabular}

\section{3. conclusion}

In this paper, through the analysis of market volatility before and after the backdoor listing of 360 Technology Limited, it is concluded that: It is not obvious that the information leakage leads to the increase of the cost of 360 Technology Limited shell borrowing. The abnormal yield of 330 days before the listing was $20.31 \%$. the analysis the change of the number of shareholders shows that there is no large-scale insider trading before the backdoor listing. However, The number of shareholders had a clear concentration trend before the suspension, Indicating the possibility of small insider trading risks and The operations are hidden and small. It is suggested to strengthen the prior supervision and punishment mechanism of information disclosure. Strengthening the identification of insider trading behavior. Taking steps to prevent information from leaking at the source, To ensure the healthy development of the securities market.

\section{References}

[1] Bing Wang, Yan Pan, Cost benefit of backdoor listing and market fluctuation, China's circulation economy, vol.6, pp. 72-81, 2017.

[2] Ping He, Research on the listing behavior of a-share backdoor listing, Finance, taxation and finance, vol.15, 2015.

[3] Biao Pang, Cocoon breaking moment--the road to the listing of express enterprises, China logistics and purchasing, vol.1, pp. 30-33, 2016.

[4] Wei Sun, Selection of listing approaches and performance difference analysis of China's securities companies, Economic landscape, vol.6, pp. 104-106, 2009.

[5] Bradley M, Jarrell G A. Expected Inflation and the Constant-Growth Valuation Model, Journal of Applied Corporate Finance, vol.20, pp. 66-78, 2010.

[6] Qun Qiu, Study on financial performance of real estate enterprises listed by shell, Finance and economics, vol.18, pp. 188-230, 2013.

[7] Jinyan Zhao, A brief analysis on the business performance of backdoor listing, Times trade, vol.13, 2016.

[8] Zhijie Yang, The secret of adverse market growth of helan house, IT manager world, vol.9, pp. 76-78, 2014. 